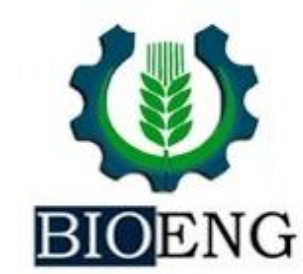

\title{
GEOTECNOLOGIAS APLICADA NOS CONFLITOS DE USO DO SOLO EM ÁREAS DE PRESERVAÇÃO PERMANENTE NO MUNICÍPIO DE BARRA BONITA/SP
}

\author{
${ }^{1}$ Faculdade de Ciências Agronômicas/UNESP, Câmpus de Botucatu-SP Brasil \\ ${ }^{2}$ Faculdade de Ciências e Engenharia/UNESP, Câmpus de Tupã- Sp Brasil
}

Article history: Received 09 March 2020; Received in revised form 07 April 2020; Accepted 01 June 2020; Available online 30 June 2020.

\section{RESUMO}

As áreas de conflito são definidas pelo mau uso do solo pelo homem e vem causando sérios problemas ao meio ambiente, resultando em desequilíbrio ecológico e desgaste dos recursos naturais, especialmente quando se refere às áreas de preservação permanente, que têm importância fundamental para os ecossistemas de equilíbrio e preservação dos recursos hídricos. O planejamento é um fator chave para o controle dos impactos ambientais ao meio ambiente. As áreas de preservação permanente evitam o assoreamento e erosão proporcionando uma proteção natural, principalmente em áreas das nascentes. Os serviços ambientais prestados auxiliam a proteção da flora e fauna, na preservação dos corredores ecológicos, e na continuação das espécies ali presentes. Este estudo teve por objetivo avaliar os conflitos de uso e ocupação da terra em áreas de Preservação Permanente do município de Barra Bonita/SP, utilizando como base cartográfica, o Sistema de Informação Geográfica (SIG) e imagem de satélite Sentinel 2-A de 2017, em escala 1:10.000. Os resultados mostraram que quase $3 / 4$ da área é ocupado com cana-de-açúcar $(72,72 \%)$ e que as áreas de preservação permanente estão sendo usados inadequadamente por cana-de-açúcar $(72,75 \%)$. O SIG ArcGis e as técnicas de geoprocessamento demonstraram agilidade e eficiência na identificação, quantificação e edição de mapas de uso do solo, preservação permanente e de conflitos em áreas de preservação permanente.

Palavras-Chave: Sistema de Informação Geográfica (SIG), Áreas de Preservação Permanente (APP) e Legislação Ambiental.

\section{GEOTECHNOLOGIES APPLIED IN THE CONFLICTS OF LAND USE IN PERMANENT PRESERVATION AREAS IN THE MUNICIPALITY OF BARRA BONITA / SP.}

\begin{abstract}
Conflict areas are defined by the misuse of land by man and have been causing serious problems to the environment, resulting in ecological imbalance and wear and tear on natural resources, especially when referring to permanent preservation areas, which are of fundamental importance for ecosystems in balance and preservation of water resources. Planning is a key factor in controlling environmental impacts on the environment. The areas of permanent preservation prevent silting and erosion, providing natural protection, especially in spring areas. The environmental services provided assist in the protection of flora and fauna, in the preservation of ecological corridors, and in the continuation of the species present there. This study aimed to evaluate the conflicts of land use and occupation in

*marcelo.campos28@unesp.br
\end{abstract}


Permanent Preservation areas of the municipality of Barra Bonita / SP, using the Geographic Information System (GIS) and Sentinel 2-A satellite image of 2017 as a cartographic base, on a 1: 10,000 scale. The results showed that almost $3 / 4$ of the area is occupied by sugarcane $(72.72 \%)$ and that the permanent preservation areas are being used inappropriately by sugarcane $(72.75 \%)$. The GIS ArcGis and geoprocessing techniques demonstrated agility and efficiency in the identification, quantification and editing of land use maps, permanent preservation and conflicts in permanent preservation areas.

Key words: Geographic Information System (GIS), Permanent Preservation Areas (APP) and Environmental Legislation

\section{INTRODUÇÃO}

O planejamento do uso do solo ao redor de microbacias é de suma importância, pois tratam-se de áreas de recarga do recurso natural água, essencial a vida dos seres vivos. Para tanto se faz necessário uma correta utilização dos recursos naturais bem como um bom aproveitamento das áreas de uso. O uso inadequado do solo gera perdas significativas ao meio ambiente e aumento de áreas conflitivas. Um bom aproveitamento das áreas de uso implica na conservação das áreas de preservação permanente (APP's) em torno dessas microbacias.

As APP's foram criadas para protegerem o ambiente natural, devendo estar sempre cobertas com a vegetação original, pois a cobertura vegetal atenua os efeitos erosivos e a lixiviação dos solos, contribuindo também para regularização do fluxo hídrico, redução do assoreamento dos cursos d'água e reservatórios, trazendo benefícios diretos para a fauna Costa et al. (1996).

Um dos grandes desafios do homem para a conservação ambiental é concentrar esforços e recursos para preservação e recuperação de áreas naturais consideradas estratégicas, das quais vários ecossistemas são dependentes. Dentre essas, destacam-se as Áreas de Preservação Permanente, que tem papel vital dentro de uma microbacia, por serem responsáveis pela manutenção e conservação dos ecossistemas ali existentes Magalhães e Ferreira (2000). Dentre os problemas mais relevantes observados nas APP's, destaca - se o histórico e contínuo desrespeito aos ecossistemas que as compõem, negligenciando-se a adoção de critérios técnicos - científicos, passando ao largo da legislação pertinente e menosprezando o saber popular.

O planejamento do uso do solo de acordo com as exigências vigentes na legislação é um processo essencial, que visa à conservação dos recursos naturais (AMATO; SUGAMOTO, 2000). Esta afirmação tem mostrado ser válida em diferentes níveis de entendimento do problema, desde o município até a unidade de produção rural. Neste sentido, a demarcação geográfica das áreas de preservação permanente (APP) destacadas pela lei, e a confrontação desses locais com o seu uso atual, estabelece as medidas a serem adotadas com o objetivo de contribuir com o uso racional das terras.

O levantamento do uso e ocupação das terras é muito importante para o planejamento da utilização racional dos recursos naturais, contribuindo na geração de informações para avaliação da sustentabilidade ambiental, pois o monitoramento das modificações de uso e ocupação das terras deve ser realizado com o acompanhado de avaliações técnicas que subsidiem a interpretação da sustentabilidade ambiental, principalmente em áreas agrícolas (FERREIRA et al., 2009).

A exploração da terra para produzir alimentos para o sustento do homem quase sempre foi de forma desordenada e sem planejamento (DAINESE, 2001), pois exploração predatória do solo causa o 
empobrecimento do solo por erosão intensa, assoreamento de cursos d'água, desertificação, entre outros.

O geoprocessamento se coloca como um importante conjunto de tecnologias de apoio ao desenvolvimento da agricultura, porque permite analisar grandes quantidades de dados georreferenciados, independentemente de serem estatísticos, dinâmicos, atuando de maneira isolada ou em conjunto (BUCENE, 2002).

O geoprocessamento pode fornecer a identificação das condições das matas ciliares, preservadas ou não preservadas, com informações que fundamentam a tomada de decisões no que se refere à reposição e recuperação das mesmas, além de subsidiar ações por parte dos órgãos ambientalistas fiscalizadores, além de constituir como ferramenta impescindível e essencial para o levantamento e monitoramento dos aspectos ambientais, auxiliando no gerenciamento dos estudos de dinâmica da paisagem, em ações fiscalizadoras, e mesmo de sensibilização ambiental (VESTENA; THOMAZ, 2006).

A manutenção da cobertura vegetal e das matas ciliares são fundamentais na conservação dos serviços ambientais (POLLO et al., 2012).

As APP ocupadas ou desmatadas indevidamentenas margens dos rios

\section{MATERIAL E MÉTODOS}

O Município de Barra Bonita/SP (Figura 1) está localizada na porção central do estado de São Paulo, situada entre as coordenadas $738.000 \mathrm{~m} \mathrm{E} ; 769.500 \mathrm{~m} \mathrm{~S}$ e $7524.000 \mathrm{~m} \mathrm{E} ; 7506.000 \mathrm{~m} \mathrm{~S}$ (projeção perdem a proteção dada pela vegetação ciliar, ficando sujeita a deslizamentos de solos e rochas e consequentemente o carreamento de sedimentos para o leito dos rios, promovendo o assoreamento, tornando-o mais rasos e em situação de precipitações mais volumosas, potencializando cheias e enchentes (SCH ̈̈FFER et al., 2011).

Os estudos ambientais mostram que a bacia hidrográfica é muito importante para nos estudos de pesquisa, pois nela podemos observar à dinâmica e a interação dos sistemas

Para que haja um planejamento de áreas agricultáveis e, proteção dos recursos naturais é necessário o conhecimento do uso e ocupação do solo, obtendo assim subsídios de análise de danos em áreas verdes, rede de drenagem e áreas urbanas, estabelecendo planos de manejo adequado.

Portanto, o presente trabalho teve por objetivo determinar as classes de uso e ocupação do solo e seus respectivos conflitos nas áreas de preservação permanente no entorno de nascentes e nas margens dos rios (cursos d'água) em função da legislação ambiental no município de Barra Bonita/SP, através de Sensoriamento Remoto e Geoprocessamento, visando à conservação dos recursos hídricos e do meio ambiente.

Universal Transversa de Mercator (UTM), fuso 22 sul, corresponde a área de 15.208,97 hectares, altitude de $460 \mathrm{~m} \mathrm{e}$ possui 36.331 habitantes (IBGE, 2017). 


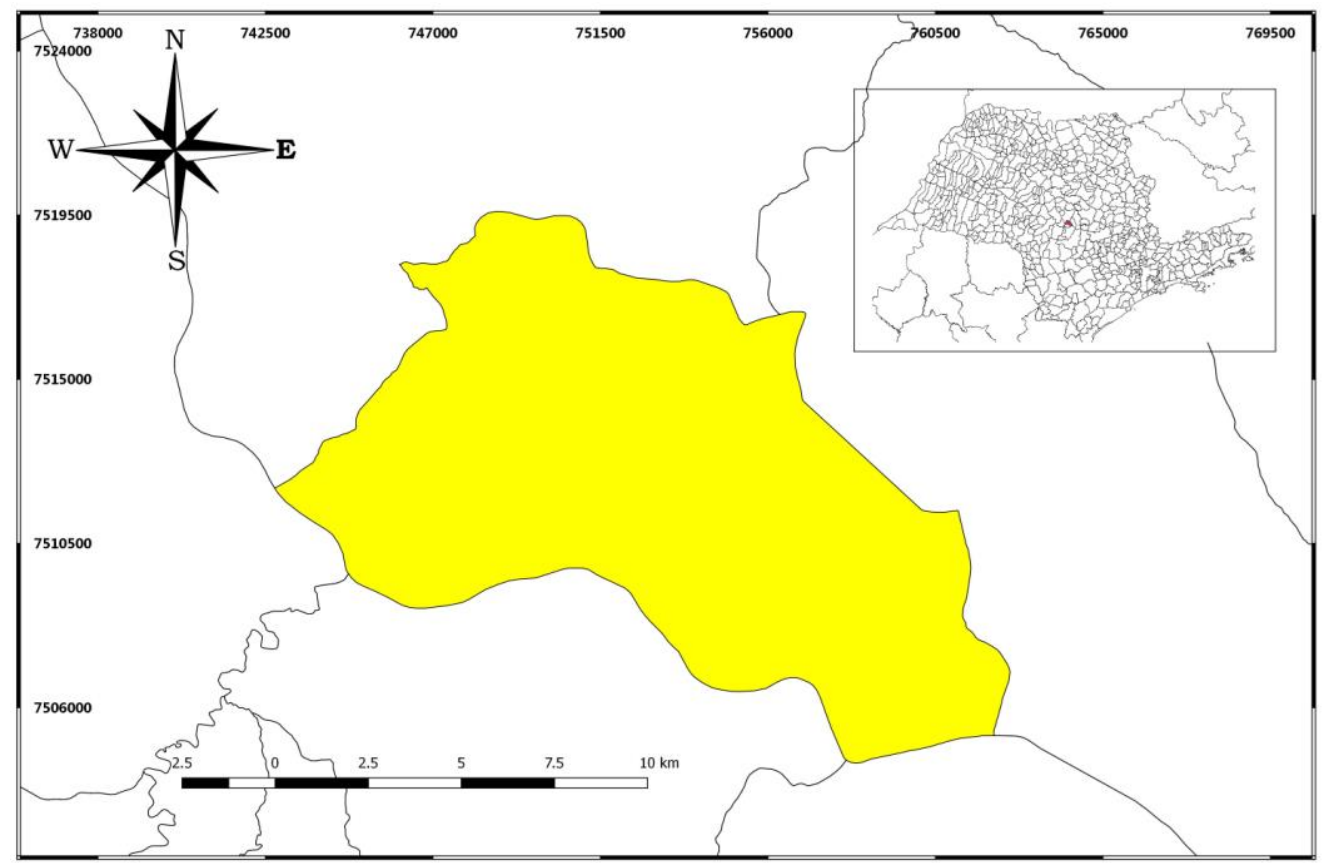

FIGURA 1. Localização do Município de Barra Bonita - SP.

O clima do município segundo classificação de Köppen é tipo Aw, tropical chuvoso com inverno seco e mês mais frio com temperatura média superior a $18^{\circ} \mathrm{C}$. O mês mais seco tem precipitação inferior a $60 \mathrm{~mm}$ e com período chuvoso que se atrasa para o outono (CEPAGRI, 2019).

Os dados espectrais foram obtidos pelo satélite Sentinel 2-A, o qual apresenta resolução espacial relativa a 10 metros, de 12 de setembro de 2017. As bandas utilizadas foram 2, 3 e 4 denominadas RGB (Red- Green- Blue), composição colorida.

As bandas espectrais, baixadas com o datum WGS 1984, foram reprojetadas para o datum SIRGAS 2000. Foi utilizado o complemento SCP (Semi-Automatic Classification Plugin) para os procedimentos de processamento da composição.

A delimitação de uma bacia hidrográfica é dada pelas linhas divisoras de água que demarcam seu contorno. Estas linhas são definidas pela conformação das curvas de nível existentes nas cartas planialtimétricas e ligam os pontos mais elevados da região em torno da drenagem, Argento e Cruz (1996).

A digitalização do limite da área foi realizada através do módulo de digitalização (digitalize) no IDRISI, utilizando-se da Carta Planialtimétrica em formato digital editada pelo Instituto Geográfico e Cartográfico do Estado de São Paulo (IGC), em escala 1:10.000, com equidistâncias das curvas de nível de 10 metros (Figura 2), Datum Córrego Alegre, Minas Gerais (IBGE, 1973). 


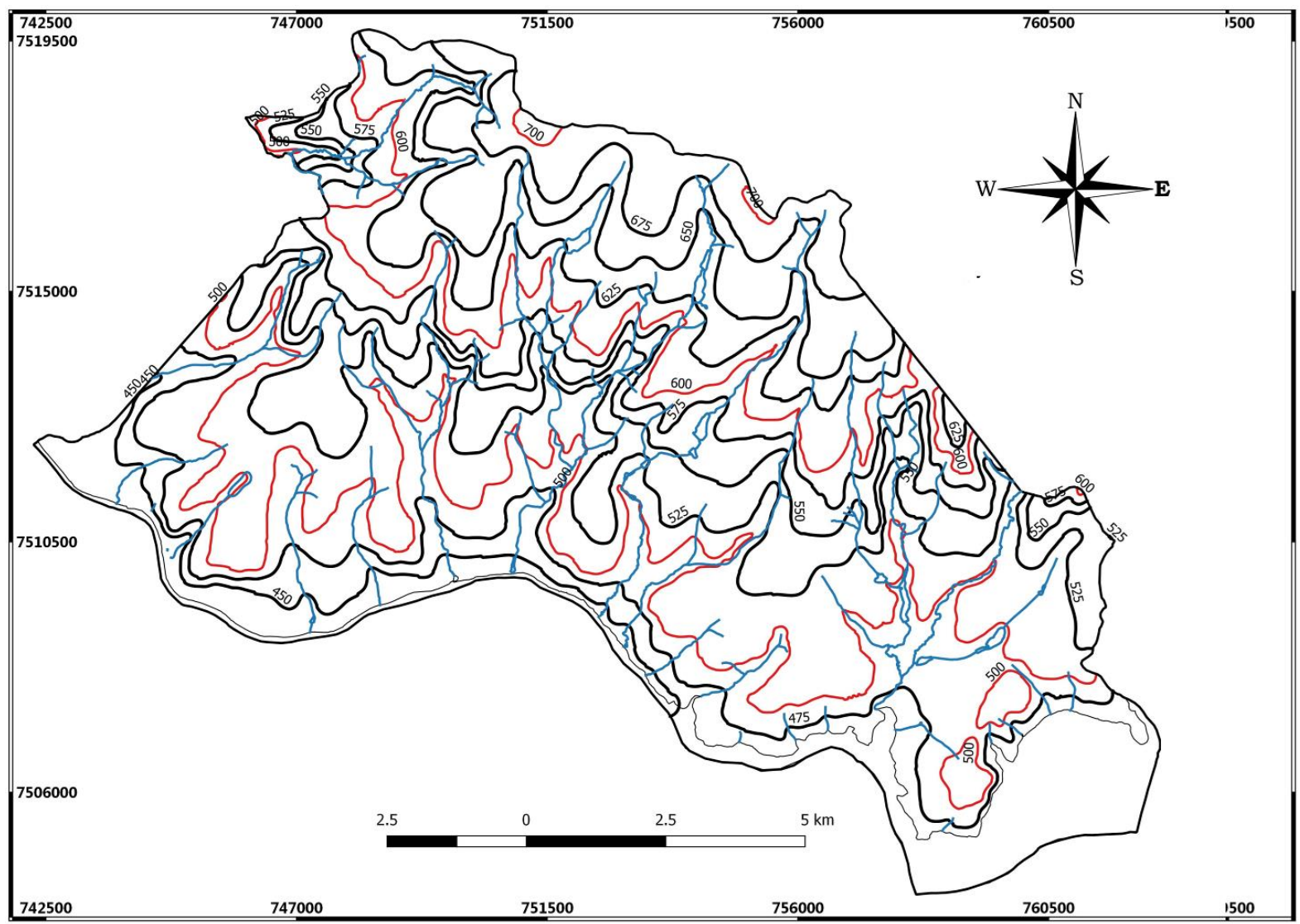

FIGURA 2. Hidrografia e planimetria do Município de Barra Bonita - SP.

$\mathrm{O}$ processo de georreferência consistiu em identificarem-se as coordenadas dos pontos de controle de tela (sob a imagem) e as coordenadas na projeção UTM nas cartas topográficas de São Manuel. Com estas informações gerou-se um arquivo de correspondência pelo módulo Data Entry/Edit, com as coordenadas $\mathrm{X}$ e $\mathrm{Y}$ de tela e seus correspondentes através do módulo Reformat/Resample.

Inicialmente, foi elaborada uma composição colorida com a combinação das bandas 3, 4 e 5, obtida a partir da imagem de satélite digital, bandas 3,4 e 5 do sensor Thematic Mapper do LANDSAT -5 , da órbita 220 , ponto 76 , quadrante A, passagem de 2009, escala 1:50000. Esta composição apresenta os corpos d'água em tons azulados, as florestas e outras formas de vegetações em tons esverdeados e os solos expostos em tons avermelhados.
No georreferenciamento foi utilizado o sistema de coordenadas planas, projeção UTM, datum Córrego Alegre, bem como dois arquivos de pontos de controle, sendo o primeiro da imagem digital e o outro, da carta topográfica de Barra Bonita, editada em 1973 pelo IBGE. Foram determinadas as coordenadas de cada ponto e com estes dados foi feito um arquivo de correspondência, através do comando Edit do menu Database Query, presente no módulo Analysis.

Após o georreferenciamento, foi feito o corte, extraindo-se apenas a área da microbacia, sendo em seguida demarcadas as áreas de treinamento sobre a imagem com o cursor e o mouse. Essas áreas foram demarcadas sobre grande número de locais, buscando-se abranger todas as variações de cada ocupação do solo (Figura 1). 


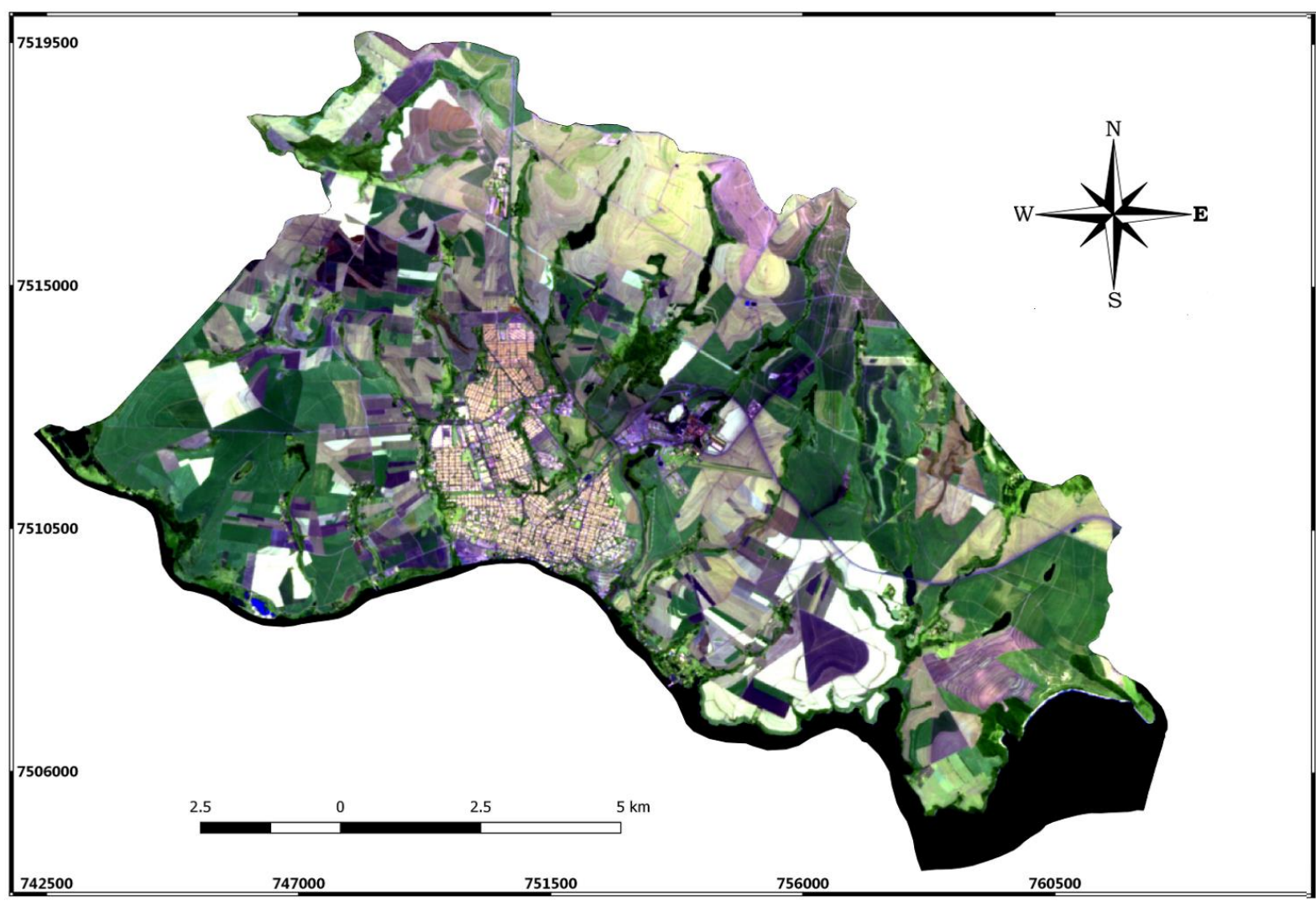

FIGURA 3. Composição falsa cor das Bandas 12, 11 e 4 do Satélite Sentinel 2-A do Município de Barra Bonita - SP.

Posteriormente, foram criadas as assinaturas pelo módulo Makesig e a classificação supervisionada propriamente dita pelo método de Máxima Verossimilhança, através do módulo Maxlike. Na classificação supervisionada, as ocupações do solo foram identificadas e diferenciadas, umas das outras pelo seu padrão de resposta espectral, sendo as áreas de treinamento delimitadas por polígonos desenhados sobre cada uso da terra na imagem.

Em seguida, foram indicados os nomes para cada classe de uso da terra, associados aos seus respectivos identificadores, sendo a imagem classificada e os cartogramas demonstrativos da distribuição espacial de cada uso da terra com base nestes dados.

$\mathrm{Na}$ identificação digital dos alvos, foram utilizadas as chaves de interpretação para imagens (Rocha, 1986) para determinação das classes de uso.

Após a elaboração da carta de uso da terra, as áreas foram determinadas com o auxílio do software SIG - IDRISI, utilizando-se do comando Area do menu
Database Query, pertencente ao módulo Analysis, sendo posteriormente determinadas as porcentagens de cada classe.

As áreas de preservação permanentes foram definidas ao longo dos cursos d'água e ao redor das nascentes do Ribeirão Santo Antonio, onde foi utilizada a operação Proximity $\rightarrow$ Buffer do Argis 9.3, que proporcionou a criação de um buffer de $50 \mathrm{~m}$ de raio nas áreas das nascentes e um buffer de $30 \mathrm{~m}$ de cada lado da drenagem ao longo do leito do córrego, com isso resultando no mapa de APP's fundamentado na resolução CONAMA ${ }^{\circ}$ 303/2002, Art. 30: "constitui Área de Preservação Permanente a área situada em faixa marginal, medida a partir do nível mais alto, em projeção horizontal, com largura mínima de trinta metros, para o curso d'água com menos de 10 metros de largura", e no Código Florestal (Lei 4.771/1965), que considera essas áreas, cobertas ou não por vegetação nativa: "com a função ambiental de preservar os recursos hídricos, a paisagem, a estabilidade geológica, a biodiversidade, o 
fluxo gênico da fauna e flora, proteger o solo e assegurar o bem-estar das populações humanas".

Para quantificar os tipos de uso conflitante utilizando-se álgebra de mapas (mapa de uso da terra x APP's) foi realizada uma sobreposição ou overlay do mapa de uso e cobertura da terra com o mapa das APP's para identificação das áreas de conflito de uso nas APP's. Os procedimentos foram executados no ArcGIS utilizando-se a opção Analysis Tools do menu ArcToolbox com o comando Intersect.

Após a sobreposição desses mapas, as áreas de ocorrência dos conflitos de acordo com as classes de uso foram identificadas e devidamente mensuradas, executando as funções de cálculo de área, através das ferramentas Calculate Geometry e Field Calculator a partir da tabela de atributos do shape. Esses procedimentos foram executados no ambiente Raster Calculator no módulo Spatial Analyst do ArcGIS e permitiram a delimitação das áreas de classes de uso da terra, qualificando e quantificando as áreas que estavam contidas nos limites das APP's, conforme procedimento metodológico (Figura 4).

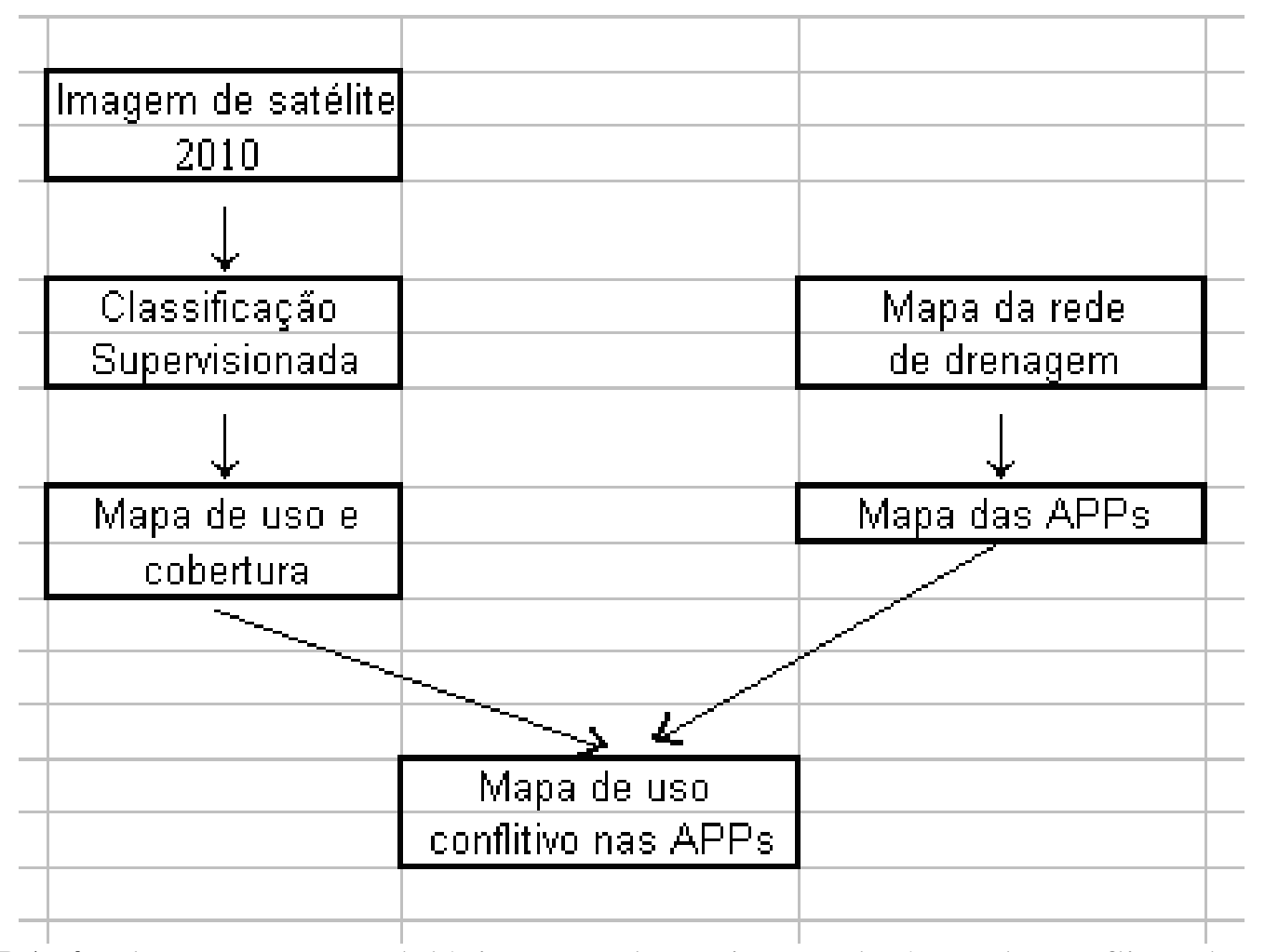

FIGURA 4. Fluxograma metodológico para determinação de áreas de conflitos de uso em APP's.

\section{RESULTADOS E DISCUSSÃO}

Os resultados (Figura 5 e Tabela 1) mostraram que a cultura de cana de açúcar é a classe predominante ocupando $72,72 \%$ do território do município, com uma grande área de expansão de canaviais. A exploração dessa matéria prima é destinada as usinas localizadas em Barra Bonita (Usina Raízen) e São Manuel (Usina São Manoel).
As matas com 1331,43 ha de vegetação nativa primária e secundária encontrada ao longo cursos d'água, nascentes e fragmentos de vegetação distribuídos não município. Sendo assim, as matas ao longo dos cursos d'água e nascentes são consideradas como Áreas de Preservação Permanente, do qual fazem a proteção e a manutenção ecológica do local, quando retiradas, podem causar a 
degradação ambiental, processo do qual afetam o equilíbrio ambiental, ocasionadas pelas ações antrópicas.

A área urbana representando 910,04 ha compreende um espaço ocupado pela cidade, destinado às atividades urbanas, onde esses espaços estão servidos de infraestrutura e serviços socioeconômicos que contextualizam a vida da população (CAMPOS, 2018).

Assim, o levantamento do uso e a cobertura da terra envolvem pesquisas de levantamento de dados e de campo, voltados para interpretação da paisagem, classificando os tipos de uso e a análise da vegetação presente, sendo de grande utilidade para o conhecimento atualizado, levantamento do uso e a cobertura da terra, observando as formas de utilização e de ocupação do espaço, atribuindo-se como ferramenta importante de planejamento e na orientação à tomada de decisão (IBGE, 2007).

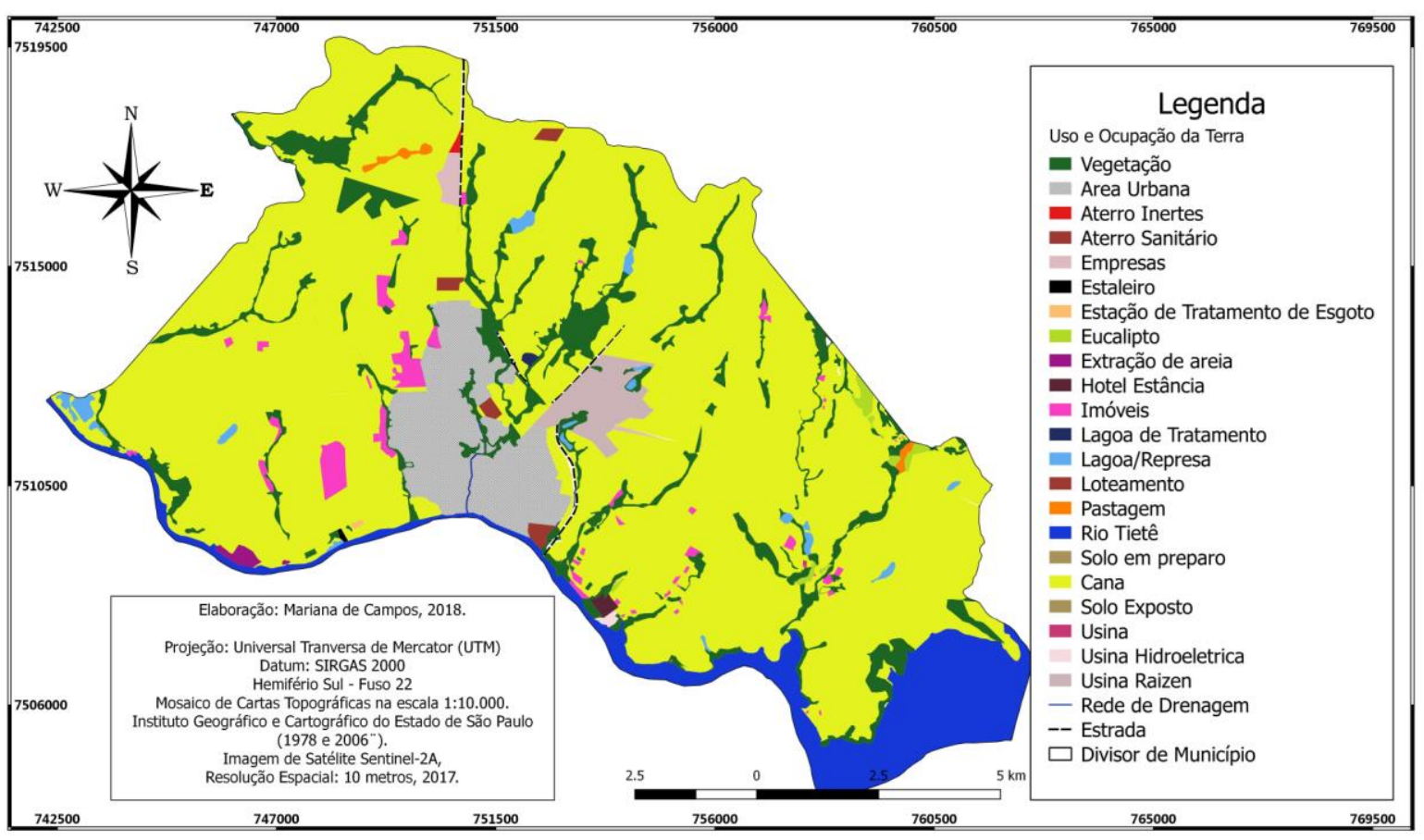

FIGURA 5. Uso e ocupação do solo do Município de Barra Bonita - SP. 
TABELA 1. Uso e ocupação do solo do Município de Barra Bonita - SP.

\begin{tabular}{|c|c|c|}
\hline \multirow[t]{2}{*}{ Classe de usos } & \multicolumn{2}{|c|}{ Área } \\
\hline & ha & $\%$ \\
\hline Mata & 1331,43 & 8,75 \\
\hline Lagoa/Represa & 101,93 & 0,67 \\
\hline Eucalipto & 41,58 & 0,27 \\
\hline Empresas & 38,35 & 0,25 \\
\hline Aterro Inertes & 6,08 & 0,04 \\
\hline Imóveis Rurais & 214,86 & 1,41 \\
\hline Loteamento & 37,07 & 0,24 \\
\hline Área Urbana & 910,04 & 5,99 \\
\hline Pastagem & 22,51 & 0,15 \\
\hline Cana-de-açúcar & 11059,67 & 72,72 \\
\hline Extração de areia & 18,43 & 0,12 \\
\hline Estaleiro & 3,00 & 0,02 \\
\hline ETE & 3,04 & 0,02 \\
\hline Lagoa de Tratamento & 6,56 & 0,04 \\
\hline Hotel & 8,84 & 0,06 \\
\hline Usina Hidrelétrica & 9,38 & 0,06 \\
\hline Aterro Sanitário & 11,77 & 0,08 \\
\hline Usina desativada & 2,00 & 0,01 \\
\hline Usina Raízen & 228,16 & 1,50 \\
\hline Rio Tietê & 1154,27 & 7,60 \\
\hline Total & $15.208,97$ & 100 \\
\hline
\end{tabular}

Os conflitos de uso pelo manejo inadequado do solo em áreas de APP, mostram que a cana de açúcar corresponde 268,39 ha $(72,75 \%)$, em virtude do solo fértil, de fácil acesso para mecanização, da vasta área para o plantio e das usinas localizadas próximo ao município de Barra Bonita (Figura 6 e Tabela 2).
O não cumprimento da legislação ambiental e a falta de planejamento do uso do solo de forma inadequada no que se referem à proteção dos cursos d'água e das nascentes do município de Barra Bonita/SP são reflexos dos conflitos existentes das ações antrópicas nas áreas que deveriam estar protegidas por lei. 
FIGURA 6. Conflitos de uso do solo em Áreas de Preservação Permanente

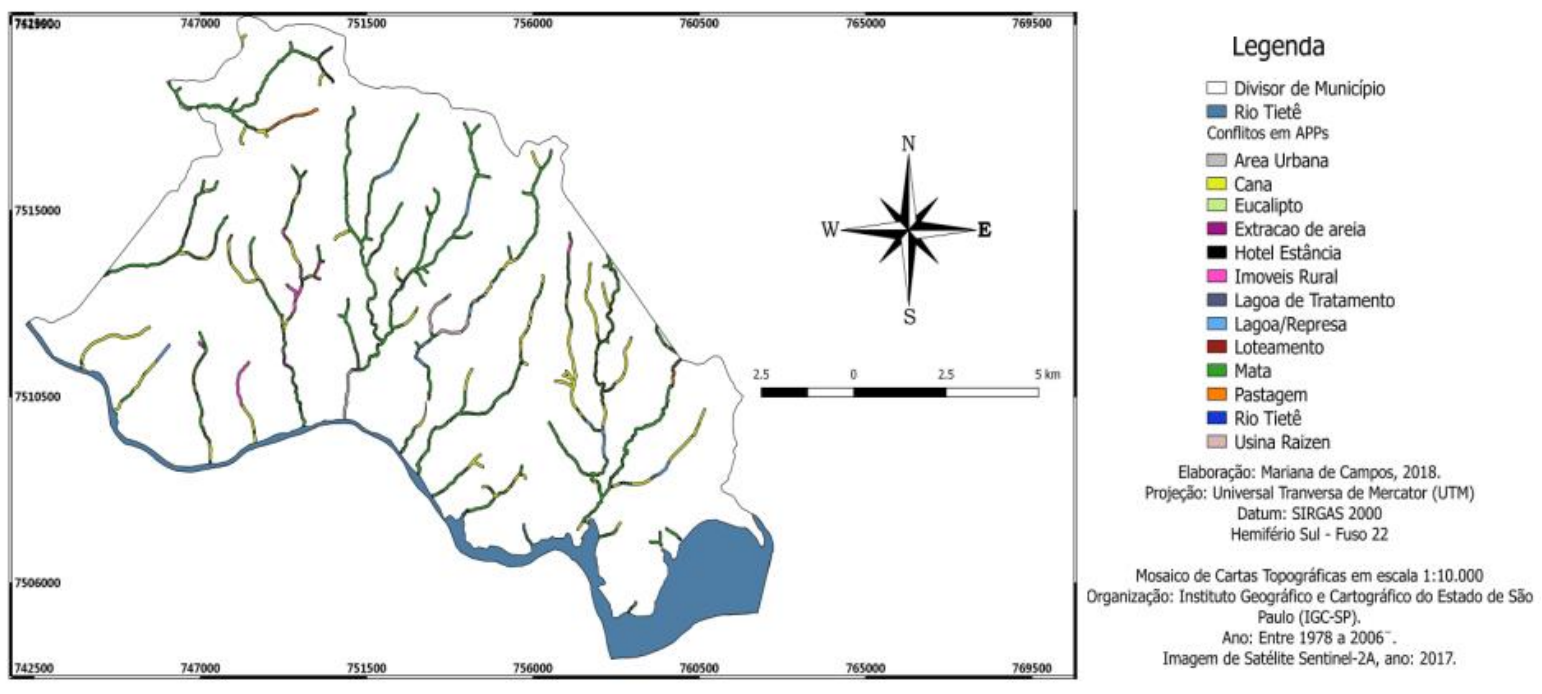

TABELA 2. Conflitos de uso da terra em APPs no município de Barra Bonita

\begin{tabular}{ccccc}
\hline Classes de usos & $\begin{array}{c}\text { APP } \\
\text { ha }\end{array}$ & $\begin{array}{c}\text { Conflitos } \\
\text { ha }\end{array}$ & $\%$ \\
\hline Mata & 437,92 & 53,84 & - & - \\
Área Urbana & 14,25 & 1,75 & 14,25 & 3,86 \\
Cana-de-açúcar & 268,39 & 33,00 & 268,39 & 72,75 \\
Eucalipto & 1,32 & 0,16 & 1,32 & 0,36 \\
Extração de areia & 0,21 & 0,02 & 0,21 & 0,06 \\
Hotel & 0,22 & 0,03 & 0,22 & 0,06 \\
Imóveis Rurais & 27,29 & 3,35 & 27,29 & 7,40 \\
Lagoa Tratamento & 0,32 & 0,04 & 0,32 & 0,09 \\
Lagoa Represa & 29,59 & 3,64 & 29,59 & 8,02 \\
Loteamento & 0,43 & 0,05 & 0,43 & 0,12 \\
Pastagem & 10,87 & 1,34 & 10,87 & 2,94 \\
Usina Raizen & 16,01 & 1,97 & 16,01 & 4,34 \\
Rio Tietê & 6,6 & 0,81 & - & - \\
\hline Total & $\mathbf{8 1 3 , 4 2}$ & $\mathbf{1 0 0}$ & $\mathbf{3 6 8 , 9 0}$ & $\mathbf{1 0 0}$
\end{tabular}

\section{CONCLUSÕES}

A utilização das imagens de satélite contribuiu para a análise do uso e ocupação do solo bem como os conflitos em APP no município de Barra Bonita/SP, pois permitiram o mapeamento do uso e ocupação do solo da cana de açúcar com $11.059,67$ ha $(72,72 \%)$, demonstrando a predominância agrícola do município.
As Áreas de Preservação Permanente com 81,42 ha, não estão sendo preservadas conforme Legislação Brasileira vigente, pois a cultura canavieira representa $o$ principal conflito de uso do solo com 72,75\% do município de Barra Bonita/SP. 


\section{REFERENCIAS}

AMATO, F., SUGAMOSTO, M. L.

Sistemas de Informações Geográficas no controle de desmatamento irregular na Área de Proteção Ambiental de Guaraqueçaba e de ocupação antrópica no entorno do Parque Nacional de Superagüi [CD-ROM]. In: GISBRASIL 2000, Salvador, 2000, Anais... Fatorgis Informação e Eventos Tecnológicos.

BRASIL. Lei ${ }^{\circ} 12.727$, de 17 de outubro de 2012. Altera a Lei no 12.651 , de 25 de maio de 2012, que dispõe sobre a proteção da vegetação nativa; altera as Leis $\mathrm{n}$ 은.938, de 31 de agosto de 1981, 9.393, de 19 de dezembro de 1996, e 11.428, de 22 de dezembro de 2006; e revoga as Leis nos 4.771 , de 15 de setembro de 1965 , e 7.754, de 14 de abril de 1989, a Medida Provisória $\mathrm{n}^{\mathrm{o}}$ 2.166-67, de 24 de agosto de 2001, o item 22 do inciso II do art. 167 da Lei no 6.015, de 31 de dezembro de 1973, e o $\S 2^{\circ}$ do art. $4^{\circ}$ da Lei $n^{\circ} 12.651$, de 25 de maio de 2012. Diário Oficial da União, Brasília, DF, 18 out. 2012. Disponível em: <http://www.planalto.gov.br/ccivil_03/_At o2011-2014/2012/Lei/L12727.htm>. Acesso em: 13 jan. 2015.

\section{BUCENE, L. C. Classificação de terras} para irrigação utilizando um sistema de informações geográficas em Botucatu SP. Botucatu, 2002. 185 p. Dissertação (Mestrado em Agronomia/Irrigação e Drenagem) - Faculdade de Ciências Agronômicas, Universidade Estadual Paulista.

\section{CAMPOS, M. Zoneamento ecológico} econômico como ferramenta para gestão ambiental no Município de Barra Bonita/SP. Botucatu, 2018. 152 p. Tese (Doutorado em Agronomia/Energia na Agricultura) - Faculdade de Ciências Agronômicas, Universidade Estadual Paulista.

CEPAGRI. Clima dos municípios paulistas. Disponível em: <http://www.cpa.unicamp.br/outrasinformacoes/clima_muni_231.html>. Acesso em: 3 jan. 2019.

COSTA, T. C. C.; SOUZA, M. G.;

BRITES, R. S. Delimitação e caracterização de áreas de preservação permanente, por meio de um sistema de informações geográficas. In SIMPÓSIO BRASILEIRO DE SENSORIAMENTO REMOTO. Anais... Salvador, INPE, 8, 1996. p.121-127.

INSTITUTO BRASILEIRO DE GEOGRAFIA E ESTATÍSTICA. Carta topográfica: folha de São Manuel - SF-22Z-B-V-2. Serviço gráfico do IBGE, 1973. Escala 1:50.000.

MAGALHÃES, C. S.; FERREIRA, R. M. Áreas de preservação permanente em uma microbacia. Informe Agropecuário, Belo Horizonte. V.21, n.207, p. 33-39, 2000.

POLLO, R. A. et al. Caracterização morfométrica da microbacia do Ribeirão Água da Lucia, Botucatu - SP. Revista Brasileira de Tecnologia Aplicada nas Ciências Agrárias, Guarapuava, v. 5, n. 1, p. 163-174, 2012.

RODRIGUES, B. M.; COSTA, A. P. L.; BOIN, M. N. Planejamento ambiental dos recursos hídricos na bacia do ribeirão anhumas, município de Anhumas - SP. Revista Colloquium Exactarum, vol. 5, 2013, p. 213-219. Disponível em: http://www.unoeste.br/site/enepe/2013/ pdf. Acesso em: 3 jun. 2017.

ROSA, M. D. A relevância ambiental das áreas de APP e sua função jurídica. 2011 Disponível em:

<periodicos.unifap.br/index.php/planeta/art icle/download/423/386>.

Acesso em: 8 set. 2017.

SCHÄFFER, W. B.; ROSA, M. R.; AQUINO, L.C.S.; MEDEIROS, J. D. 
Áreas de SEMA Preservação

Permanente e Unidades de Conservação

X Áreas de Risco. O que uma coisa tem a ver com a outra? Relatório de Inspeção da área atingida pela tragédia das chuvas na Região Serrana do Rio de Janeiro. Brasília: MMA, 2011.
VESTENA, R. L.; THOMAZ, E. L. Avaliação de conflitos entre áreas de preservação permanente associadas aos cursos fluviais e uso da terra na bacia do Rio das Pedras, Guarapuava - PR. Revista Ambiência, Guarapuava, v.2, n.1, p 73-75, 2006. 